\title{
Cadherin 26 is an alpha integrin-binding epithelial receptor regulated during allergic inflammation
}

\author{
JM Caldwell ${ }^{1}$, MH Collins ${ }^{2}$, KA Kemme ${ }^{1}$, JD Sherrill ${ }^{1}$, T Wen ${ }^{1}$, M Rochman ${ }^{1}$, EM Stucke ${ }^{1}$, L Amin $^{1}$, H Tai $^{1}$, \\ PE Putnam ${ }^{3}$, MJ Jiménez-Dalmaroni ${ }^{4}, \mathrm{MR}_{\text {Wormald }}{ }^{5}$, A Porollo $^{6}$, JP Abonia ${ }^{1}$ and ME Rothenberg ${ }^{1}$
}

Cadherins (CDH) mediate diverse processes critical in inflammation, including cell adhesion, migration, and differentiation. Herein, we report that the uncharacterized cadherin 26 (CDH26) is highly expressed by epithelial cells in human allergic gastrointestinal tissue. In vitro, CDH26 promotes calcium-dependent cellular adhesion of cells lacking endogenous $\mathrm{CDH}$ s by a mechanism involving homotypic binding and interaction with catenin family members (alpha, beta, and p120), as assessed by biochemical assays. Additionally, $\mathrm{CDH} 26$ enhances cellular adhesion to recombinant integrin $\alpha 4 \beta 7$ in vitro; conversely, recombinant $\mathrm{CDH} 26$ binds $\alpha \mathrm{E}$ and $\alpha 4$ integrins in biochemical and cellular functional assays, respectively. Interestingly, CDH26-Fc inhibits activation of human CD4 ${ }^{+}$Tcells in vitro including secretion of IL2. Taken together, we have identified a novel functional $\mathrm{CDH}$ regulated during allergic responses with unique immunomodulatory properties, as it binds $\alpha 4$ and $\alpha \mathrm{E}$ integrins and regulates leukocyte adhesion and activation, and may thus represent a novel checkpoint for immune regulation and therapy via CDH26-Fc.

\section{INTRODUCTION}

Cadherins (CDHs), a family of transmembrane cell surface glycoproteins, mediate calcium-dependent cell adhesion and exhibit a tightly regulated tissue-specific expression pattern. $\mathrm{CDH}$ s expressed predominantly within epithelia such as E-cadherin $(\mathrm{CDH} 1)$ and $\mathrm{P}$-cadherin $(\mathrm{CDH} 3)^{1}$ contribute to the maintenance of skin and mucosal barriers, regulating access of pathogens and allergens to underlying tissue and immunocytes. Modulation of $\mathrm{CDH}$ expression and function has been associated with a number of diseases such as cancer, in which metastatic tumorigenesis is often associated with a switch in $\mathrm{CDH}$ expression such as $\mathrm{CDH} 1$ to $\mathrm{CDH} 2\left(\mathrm{~N}\right.$-cadherin), ${ }^{2}$ as well as diverse inflammatory diseases, including but not limited to asthma, eczema, chronic rhinosinusitis, inflammatory bowel disease, and rheumatoid arthritis. ${ }^{3-7}$ Focusing on epithelial $\mathrm{CDHs}$, reduced CDH1 occurs in gastroesophageal reflux disease, asthma, and eczema and has been shown to contribute to loss of epithelial integrity, impairment of barrier function, and production of pro-inflammatory cytokines. ${ }^{6,8-10} \mathrm{~A}$ substantial advance in the $\mathrm{CDH}$ field has been the finding that $\mathrm{CDH} 1$ binds lymphocyte integrin $\alpha \mathrm{E} \beta 7$ and regulates the activation and localization of epidermal and intestinal intraepithelial lymphocytes. ${ }^{11-14}$ Despite these observations regarding $\mathrm{CDH} 1$, the involvement of other $\mathrm{CDH}$ s in the regulation of immunological processes mediated by the mucosal epithelium, such as their binding to integrins, has not been described.

Allergic disorders are characterized by a T helper type 2 (Th2) immune response that involves the accumulation of distinct subsets of activated leukocytes at the affected site. In particular, in addition to eosinophils, increased numbers of $\mathrm{CD}^{+} \mathrm{T}$ cells and type 2 innate lymphoid cells have been observed at sites of allergic gastrointestinal (GI) inflammation. ${ }^{15-18}$ Furthermore, highly elevated levels of Th2 cytokines, including interleukin (IL)-13, suggest activation of these cells at sites of allergic GI inflammation. ${ }^{19,20}$ In general, it is known that leukocytes, in part under the influence of soluble mediators including cytokines and chemokines, localize from the blood to tissue in a multi-step process involving the coordinate

${ }^{1}$ Division of Allergy and Immunology, Cincinnati Children's Hospital Medical Center, University of Cincinnati College of Medicine, Cincinnati, Ohio, USA. ${ }^{2}$ Division of Pathology and Laboratory Medicine, Cincinnati Children's Hospital Medical Center, University of Cincinnati College of Medicine, Cincinnati, Ohio, USA. ${ }^{3}$ Division of Gastroenterology, Hepatology and Nutrition, Cincinnati Children's Hospital Medical Center, University of Cincinnati College of Medicine, Cincinnati, Ohio, USA. ^Department of Biological Chemistry, John Innes Centre, The Sainsbury Laboratory, Norwich, UK. ${ }^{5}$ The Glycobiology Institute, Department of Biochemistry, University of Oxford, Oxford, UK and ${ }^{6}$ Center for Autoimmune Genomics and Etiology, Division of Biomedical Informatics, Cincinnati Children's Hospital Medical Center, University of Cincinnati College of Medicine, Cincinnati, Ohio, USA. Correspondence: ME Rothenberg (Rothenberg@cchmc.org) 
expression and activation of leukocyte-expressed selectins and integrins and their counter-receptors on activated endothelium. ${ }^{21}$ However, less is known about how leukocyte-expressed receptors interact with epithelial ligands to influence cellular localization and activation, particularly in the context of allergic inflammation.

We identified a previously uncharacterized $\mathrm{CDH}$-like molecule, $\mathrm{CDH} 26$, that was markedly overexpressed in human GI tissue with active eosinophilic inflammation. ${ }^{20}$ No studies of this molecule have been reported, although its transcript appears to be upregulated in epithelial cells under Th2associated conditions. ${ }^{22-25}$ Herein we demonstrate that $\mathrm{CDH} 26$ is a unique functional $\mathrm{CDH}$, in that it (1) has an epithelial cell-restricted expression pattern that is particularly prominent following gene induction during allergic inflammation; (2) is an $\alpha 4$ and $\alpha \mathrm{E}$ integrin receptor; (3) has the capacity to modulate leukocyte adhesion and activation; and (4) has immunomodulatory function that can be exploited via a $\mathrm{CDH} 26-\mathrm{Fc}$ fusion protein, which has immunosuppressive activity.

\section{RESULTS}

\section{CDH26 is overexpressed during pathological allergic inflammation}

Gastric tissue of control patients and patients with an allergic gastroenteropathy, eosinophilic gastritis (EG), was subjected to global transcript analysis. ${ }^{20}$ Additional information about these patients can be found in Supplementary Methods and Supplementary Table S2 online. We identified that the most upregulated transcript that passed the criteria $P<0.01$ and 2-fold filter was the uncharacterized $\mathrm{CDH}$ family member cadherin 26 (CDH26) $(12.3$-fold, $P<0.005) .{ }^{20}$ We verified by real-time PCR analysis that the $C D H 26$ mRNA level was highly increased in the gastric tissue of EG patients within the same cohort subjected to microarray (15.3-fold, $n=5$ EG vs. $n=5$ control, $P=0.03$; see Supplementary Figure S1a) as well as in additional EG patient gastric tissue (35.6 fold, $n=10$ EG vs. $n=10$ control, $P<0.0001$; see Supplementary Figure S1b). Comparison of the genes differentially regulated in $\mathrm{EG}^{20}$ and in eosinophilic esophagitis $(\mathrm{EoE})^{26}$ revealed that $\mathrm{CDH} 26$ was the only $\mathrm{CDH}$ family member that exhibited a significant change in gene expression in both allergic disorders. Indeed, as previously observed, ${ }^{19}$ CDH26 mRNA expression was significantly increased (115-fold) in the esophageal tissue of patients with active EoE compared with control patients (Figure 1a). Only CDH1 (E-cadherin) and $\mathrm{CDH} 26$ exhibited raw signals indicative of the transcripts being substantially expressed (i.e., at least one sample for that probe exhibited raw signal $\geqslant 400)$ in the gastric tissue of patients with active EG (Figure 1b). Raw signals for $\mathrm{CDH}$ transcripts in esophageal tissue from EoE patients only showed such values for $\mathrm{CDH}$, $\mathrm{CDH} 3$ (P-cadherin), and $\mathrm{CDH} 26$ (Figure 1c). As a control, no significant change in $\mathrm{CDH} 26$ or CCL26 (eotaxin-3) expression was observed in gastric tissue of patients with Helicobacter pylori gastritis compared with control patients, although control C3 transcript was elevated in the $H$. pylori cohort as previously reported (Figure 1d and Ikuse et al. ${ }^{27}$ and Wen et al. $\left.{ }^{28}\right)$. Notably, a microarray study of gastric antrum tissue of patients with $\mathrm{H}$. pylori gastritis did not identify $\mathrm{CDH} 26$ as being upregulated compared with normal tissue. ${ }^{27}$ Thus, $\mathrm{CDH} 26$ is a unique $\mathrm{CDH}$ in terms of its expression level and regulation in two distinct allergic states.

\section{CDH26 protein expression is increased in inflamed allergic GI tissue and is localized to epithelial cells}

Immunohistochemical staining for $\mathrm{CDH} 26$ showed localization nearly exclusively in the surface and gland epithelial cells in gastric tissue of patients with EG (Figure 2a,b). The mean peak number of $\mathrm{CDH} 26$-positive cells was 241 cells $/ \times 400$ highpower field (mean \pm s.e.m., $104.2 \pm 40.8$; $P=0.0476$, MannWhitney test) in EG patients compared with no expression above background in controls. Western blotting revealed an increased level of gastric $\mathrm{CDH} 26$ (4.9-fold) in EG patients compared with control samples (Figure 2c). Patients with active EoE had high levels of esophageal $\mathrm{CDH} 26$ protein expression compared with control patients. In control esophageal biopsies, the staining was confined to epithelial cells near the surface, but in active EoE the staining was both more intense and prevalent and included both surface epithelial cells and epithelial cells in the expanded basal layer (Figure 2d). By western blotting analysis, esophageal tissue of EoE patients showed 3.4-fold increased $\mathrm{CDH} 26$ protein levels compared with control tissue (Figure 2e).

\section{CDH26 is a functional CDH}

$\mathrm{CDH} 26$ exhibits sequence homology to the $\mathrm{CDH}$ family of proteins, with five extracellular $\mathrm{CDH}$ repeats ${ }^{29}$ in the putative extracellular portion of the protein, a predicted transmembrane domain, and a C-terminal cytoplasmic region (Figure 3a). To determine whether $\mathrm{CDH} 26$ localized to the cell membrane of esophageal epithelial cells, affinity isolation of biotinylated surface proteins was performed. Proteins present on the surface of cells were labeled with biotin, the cells were lysed and proteins solubilized, and biotinylated proteins were subjected to affinity isolation using streptavidin beads. Proteins bound to the streptavidin beads were subsequently solubilized in loading buffer and subjected to sodium dodecyl sulfate-polyacrylamide gel electrophoresis (SDS-PAGE). Western blotting for $\mathrm{CDH} 26$ indicated that it was present at the cell surface in esophageal epithelial cells that express high levels of CDH26 (Figure 3b) because it was pulled down only from cells overexpessing $\mathrm{CDH} 26$ that underwent surface biotinylation (Figure $\mathbf{3 b}$, lane 8).

$\mathrm{CDH} 26$ contains five asparagine residues in its extracellular domain; these residues are located within the consensus sequence for $\mathrm{N}$-linked glycosylation (N81, N85, N171, N177, N462). To test whether $\mathrm{CDH} 26$ is modified by $N$-linked glycosylation, $\mathrm{CDH} 26$ was immunoprecipitated and then treated with peptide: $N$-glycosidase F (PNGase F) that was either active or heat-inactivated as a negative control. The treated, immunoprecipitated proteins were then subjected to SDS-PAGE and western blotting analysis for $\mathrm{CDH} 26$. Immunoprecipitated $\mathrm{CDH} 26$ treated with peptide: $\mathrm{N}$-glycosidase 
a

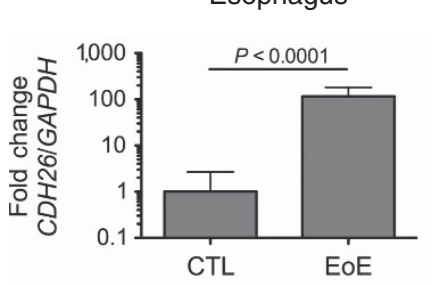

d

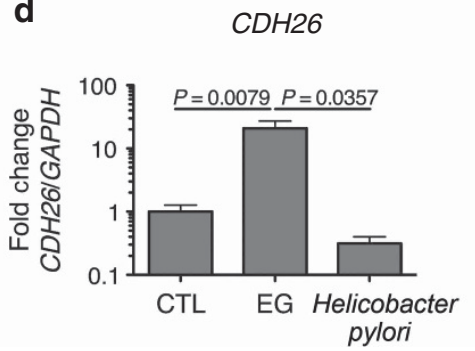

b

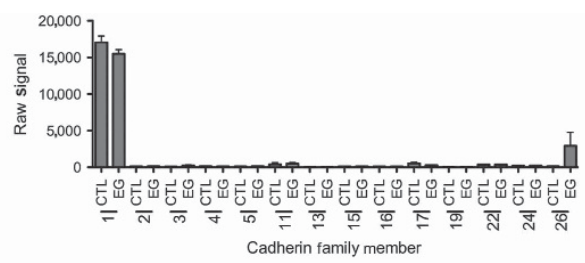

CCL26

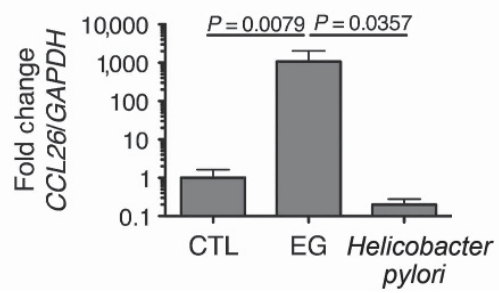

C

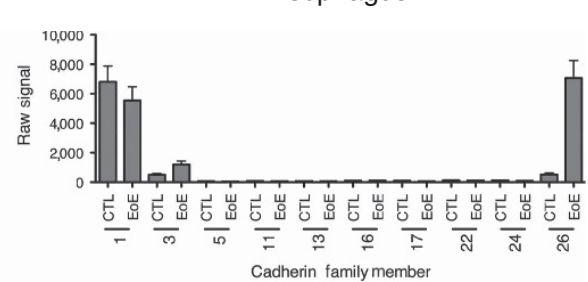

C3

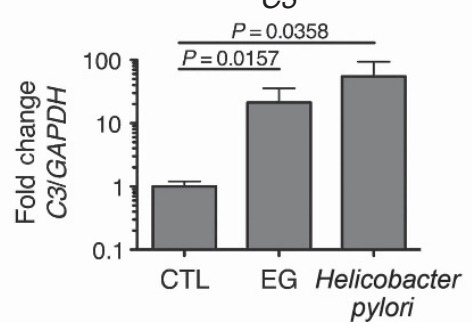

Figure 1 Cadherin $26(C D H 26)$ expression in allergic tissue. (a) Relative esophageal tissue $C D H 26$ transcript levels were determined $(n=66$ control (CTL), $n=77$ eosinophilic esophagitis (EoE) patients). The bars represent the median, and the error bars represent the interquartile range (b and $\mathbf{c})$. The mean raw expression value (bars) for each cadherin probe in which any patient sample exhibited a signal intensity $>100$ is graphed for (b) the gastric tissue of $5 \mathrm{CTL}$ and 5 eosinophilic gastritis (EG) patients ${ }^{20}$ or for (c) the esophageal tissue of $14 \mathrm{CTL}$ and 18 EoE patients characterized previously. ${ }^{26}$ For each cadherin, only the probe with the highest raw signal is shown. For (b and c), error bars represent the s.e.m. (d) Relative CDH26, CCL26 (eotaxin-3), and C3transcript levels from the gastric antrum tissue of CTL patients $(n=5)$, EG patients $(n=5)$, and H. pylori gastritis patients $(n=3)$ were determined. The bars represent the mean, and error bars represent the s.e.m. For (a and d), data were analyzed by Mann-Whitney test.

F (PNGase F) (Figure 3c, lane 5), but not heat-inactivated PNGase F (Figure 3c, lane 6), exhibited increased mobility compared with $\mathrm{CDH} 26$ from total cell lysates, indicating that the protein is modified by $\mathrm{N}$-linked glycosylation under baseline conditions.

$\mathrm{CDH} 26$ contains a tryptophan residue at position 2 of the most $\mathrm{N}$-terminal extracellular $\mathrm{CDH}$ repeat domain known to be critical for dimerization in trans of type I and type II CDHs. ${ }^{30}$ Therefore, we tested whether $\mathrm{CDH} 26$ molecules interact in a homotypic manner. When co-expressed, myc-tagged $\mathrm{CDH} 26$ co-immunoprecipitated with hemagglutinin (HA)-tagged $\mathrm{CDH} 26$ (Figure 3d, lane 7), and the reciprocal immunoprecipitation (IP) confirmed that CDH26-HA coimmunoprecipitated with CDH26-MYC (Figure 3d, lane 8).

We next tested whether $\mathrm{CDH} 26$ interacted with betacatenin, which binds other $\mathrm{CDH}$ molecules to link them indirectly to the actin cytoskeleton. ${ }^{30-32}$ The region of $\mathrm{CDH} 1$ known to interact with beta-catenin exhibited $68 \%$ similarity to the same region of CDH26 (Stappert and Kamler ${ }^{31}$ and Jou et $a .^{32}$, see Supplementary Figure S2a,b,d). When IP of HAtagged beta-catenin was performed, $\mathrm{CDH} 26$ was also detected in the precipitates (Figure 3e, lanes 7 and 9), indicating that beta-catenin and CDH26 exist in the same complex.

Beta-catenin interacts with alpha-catenin to link $\mathrm{CDH}$ molecules indirectly to the actin cytoskeleton and thus support cell adhesion. ${ }^{30}$ We tested whether alpha-catenin exists in the same complex as $\mathrm{CDH} 26$ and found that $\mathrm{CDH} 26$ coimmunoprecipitated with alpha-catenin (Figure 3f, lane 6). As a positive control, beta-catenin was also observed to coimmunoprecipitate with alpha-catenin (Figure 3f, lane 6).

p120-catenin binds the juxtamembrane domain of the cytoplasmic portion of $\mathrm{CDH}$ molecules and has been shown to function in the maintenance of $\mathrm{CDH}$ stability and localization to the cell surface. ${ }^{30}$ The primary amino-acid sequence of the juxtamembrane domain of $\mathrm{CDH} 1$ was notably homologous (48\%) to that in CDH26 (see Supplementary Figure S2a,c,d). We therefore tested whether $\mathrm{CDH} 26$ and p120-catenin could exist in the same protein complex and found that p120-catenin and $\mathrm{CDH} 26$ co-immunoprecipitated (Figure 3g, lane 9).

We tested whether $\mathrm{CDH} 26$ could promote calcium-dependent cellular adhesion. To do this, L929 cells, which lack endogenous CDHs, were used in an aggregation assay. L929 cells that were transduced with a $\mathrm{CDH} 26$ expression construct and thus expressed high levels of $\mathrm{CDH} 26$ showed a high degree of aggregation only in the presence of calcium (Figure $\mathbf{3 h}$, column 4 vs. column 3 ), whereas cells transduced with a control expression construct aggregated neither in the presence nor in the absence of calcium (Figure $\mathbf{3 h}$, columns 1 and 2).

\section{CDH26 binds $\alpha 4$ and $\alpha E$ integrins}

Heterotypic binding of $\mathrm{CDHs}$ and integrins has been reported. ${ }^{12,33}$ There are a number of proteins known to bind integrins, including CDH1 as well as ICAM-1 (intercellular adhesion molecule 1), MAdCAM-1 (mucosal addressin cell adhesion molecule 1), and fibronectin, for which 3D structures have been resolved and integrin-binding sites have been localized. ${ }^{34}$ To map these sites to $\mathrm{CDH} 26$, we generated a 3D model of $\mathrm{CDH} 26$ structure using homology modeling with the $\mathrm{CDH} 1$ structure (PDB ID 3Q2V) as a primary template. The pairwise structure alignment of the model (blue) with other resolved structures (gray) indicates putative integrin-binding sites in CDH26 (Figure 4a). As can be seen, known integrinbinding sites are located in the unstructured loops of 
a
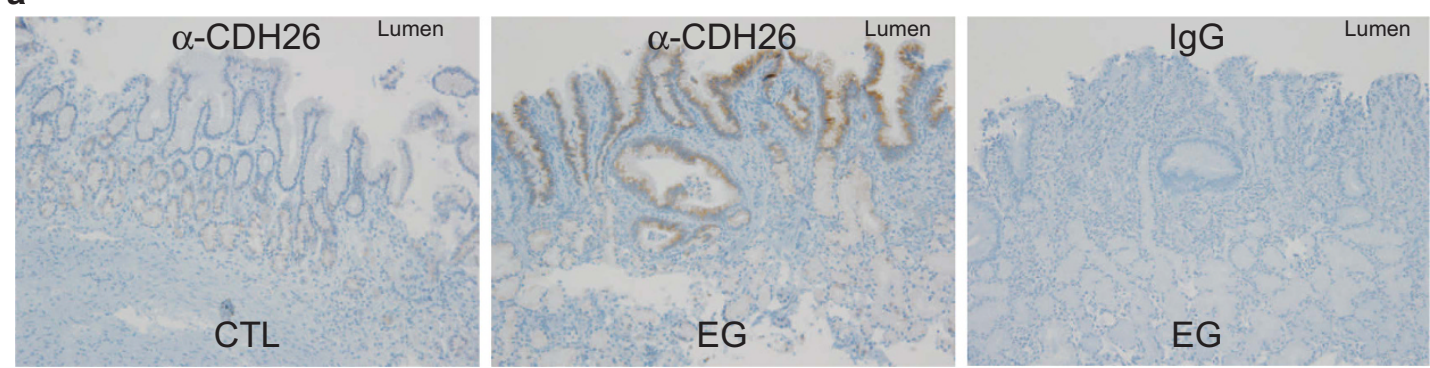

b
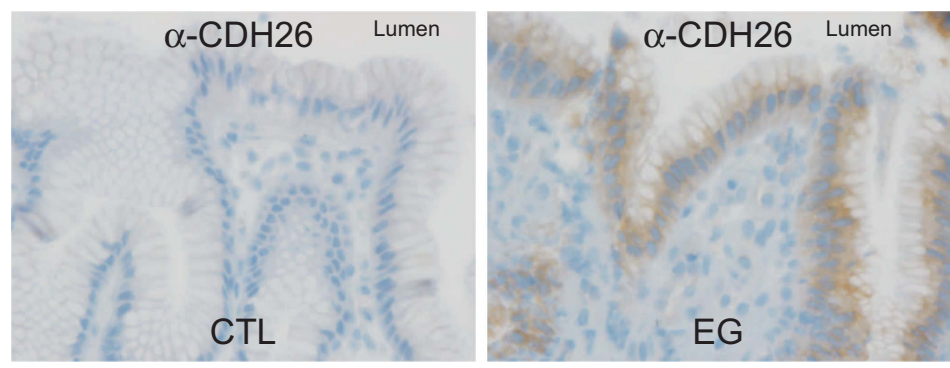

C
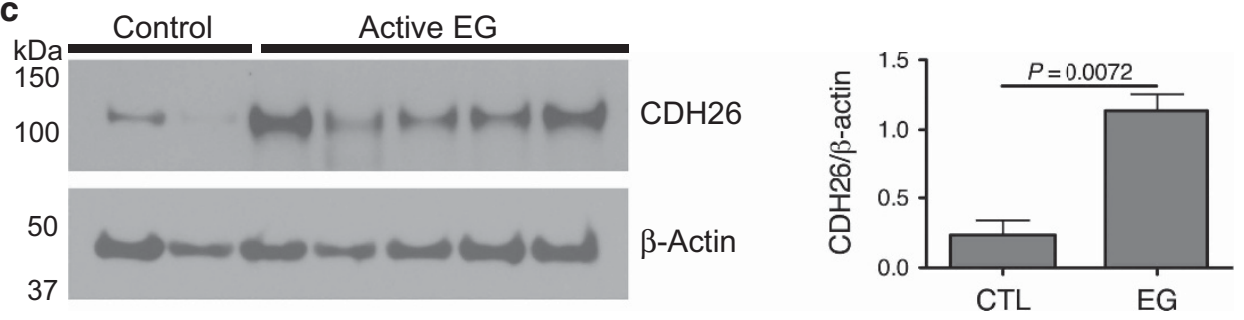

d
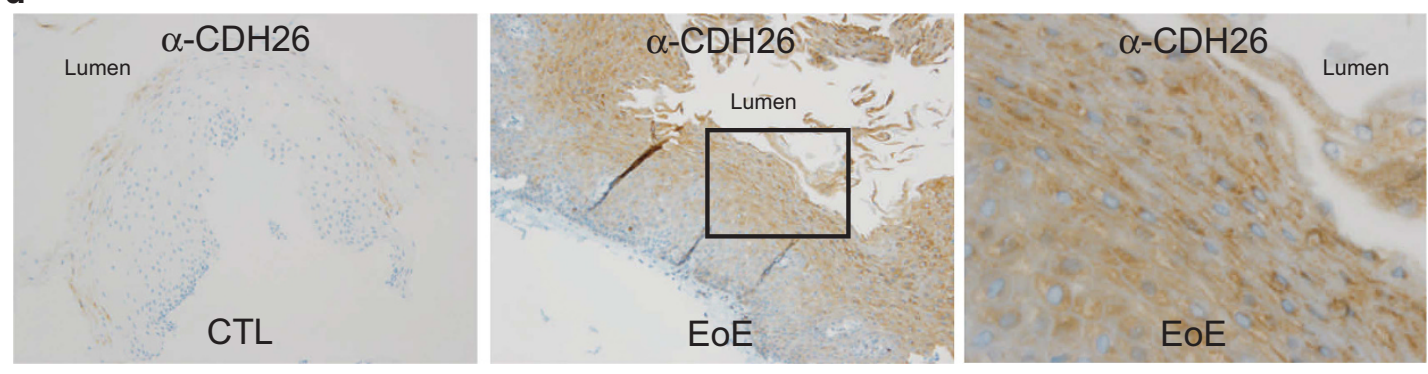

e
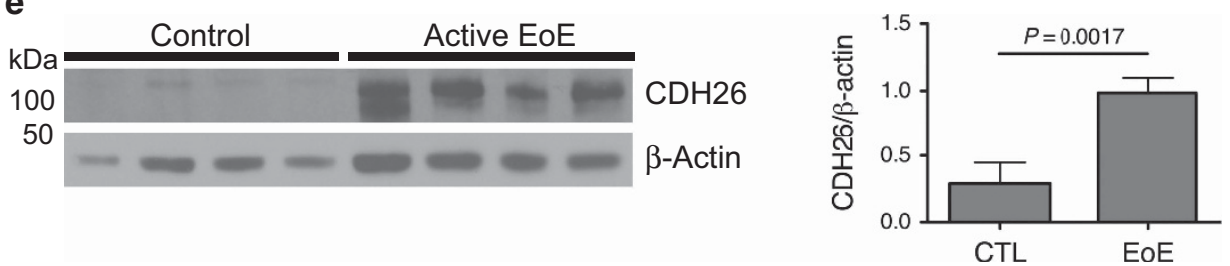

Figure 2 Cadherin $26(\mathrm{CDH} 26)$ expression and localization in epithelial cells in allergic gastrointestinal tissue. (a) Representative control (CTL) and eosinophilic gastritis $(E G)$ patient gastric biopsy specimen $(\times 200)$ stained with anti-CDH26 antibody or control immunoglobulin $G$ (IgG). (b) CTL and EG biopsy specimen $(\times 800)$ stained with anti-CDH26 antibody. (c) Left: Gastric antrum protein lysates were subjected to sodium dodecyl sulfatepolyacrylamide gel electrophoresis (SDS-PAGE) and western blotting analysis. Right: The ratio of CDH26 to beta-actin signal was graphed; bars represent the mean, and error bars represent the s.e.m. (d) Immunohistochemical staining for CDH26 was performed on esophageal biopsy specimens ( $n=7$ CTL, $n=3$ EoE). Representative CTL and EoE biopsies are shown ( $\times 200, \times 800$ inset). (e) Left: Esophageal protein lysates ( $n=4 \mathrm{CTL}, n=4$ EoE) were subjected to SDS-PAGE and western blotting analysis. Right: The ratio of CDH26 to beta-actin signal was graphed; bars represent the mean, and error bars represent the s.e.m. For $\mathbf{c}$ and $\mathbf{e}$, data were analyzed by unpaired $t$-test. For (a, $\mathbf{b}$, and $\mathbf{d})$, the location of the lumen is denoted to facilitate interpretation of the orientation of the tissue section. 
a

\begin{tabular}{|c|c|c|c|c|c|c|c|c|}
\hline S & EC1 & EC2 & EC3 & EC4 & EC5 & $|\mathrm{T}|$ & JMD & C \\
\hline
\end{tabular}

b

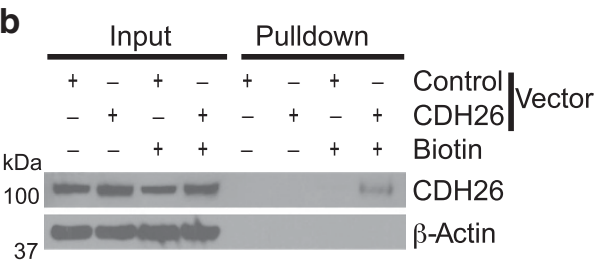

C

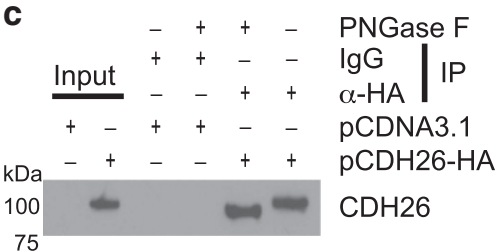

d

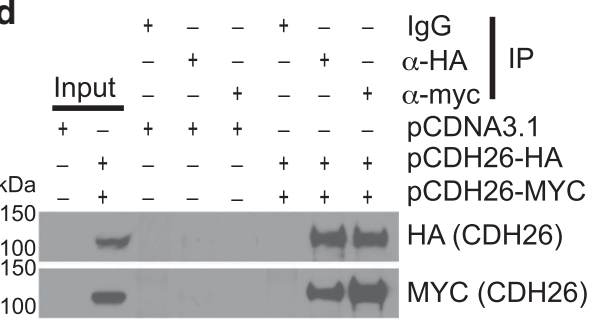

e

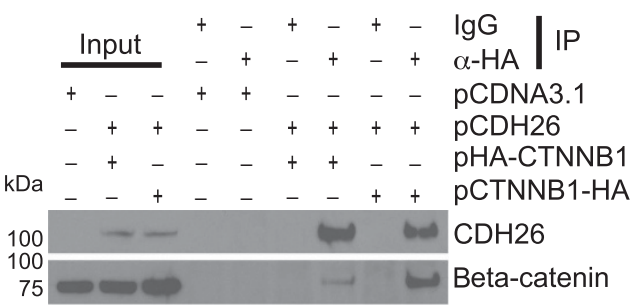

f
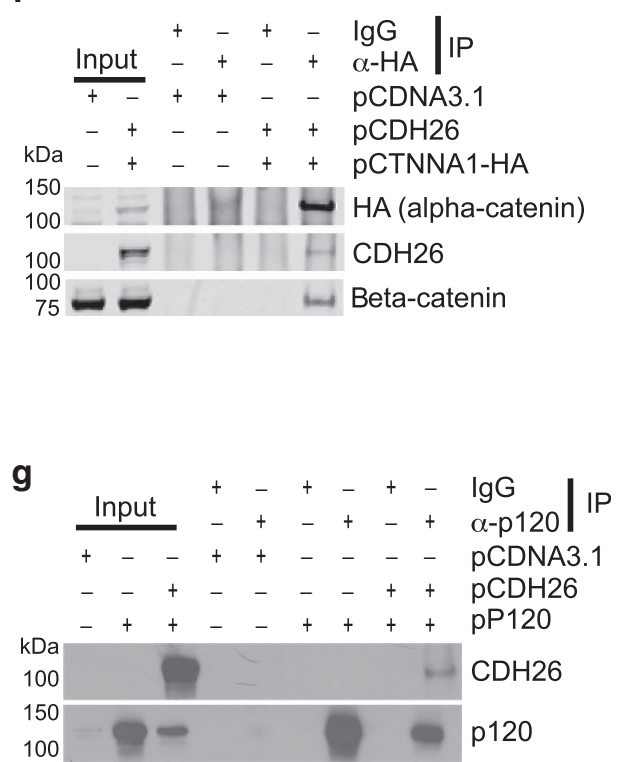

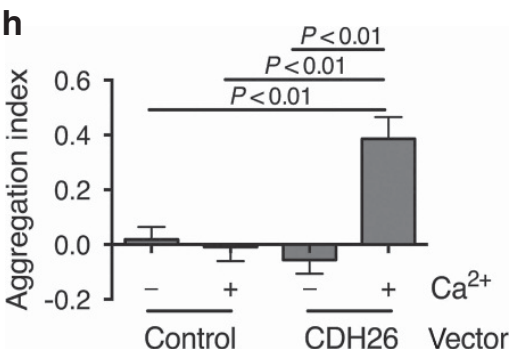

Figure 3 Biochemical and functional properties of cadherin 26 (CDH26). (a) Schematic representing human $\mathrm{CDH} 26$ domain structure. S: signal peptide, EC1-EC5: extracellular cadherin repeat 1-5, T: transmembrane domain, JMD: juxtamembrane domain, C: CBD, catenin-binding domain. (b) Surface biotinylation of TE-7 cells. Cell surface proteins were labeled with biotin and pulled down with streptavidin beads. Total cell lysates (input) and proteins bound to the streptavidin beads were subjected to sodium dodecyl sulfate-polyacrylamide gel electrophoresis (SDS-PAGE) and western blotting analysis. Predicted CDH26 molecular weight: $92.4 \mathrm{kDa}$. (c) Immunoprecipitates from transiently transfected HEK $293 \mathrm{~T}$ cells were treated with either peptide: $N$-glycosidase F (PNGase F) (+) or heat-inactivated PNGase F ( - ). Inputs (1/10 of amount used for immunoprecipitation (IP)) and treated immunoprecipitates were subjected to SDS-PAGE and western blotting analysis. Each blot shown is representative of three independent experiments. (d- $\mathbf{g})$ Immunoprecipitates from transiently transfected HEK 293T cells and inputs (1/10 of amount used for IP) were subjected to SDSPAGE and western blotting analysis. Each blot shown is representative of three independent experiments. (h) Transduced L929 cells were dispersed, incubated in buffer either containing or lacking $1 \mathrm{~mm} \mathrm{CaCl}$, and assessed for the degree of aggregation. Bars represent the mean, and error bars represent the s.e.m. Data show one experiment representative of three and were analyzed by one-way analysis of variance followed by Tukey's posttest.

extracellular domain and are negatively charged. D42 of MAdCAM-1 and E34 of ICAM-1 overlap with D98, E99, and E102 in CDH26. D1495 of fibronectin corresponds to E138 of $\mathrm{CDH} 26$. The presence of these negatively charged residues in the unstructured loops on the surface suggests that $\mathrm{CDH} 26$ would bind integrins.

We tested whether L929 cells expressing high levels of $\mathrm{CDH} 26$ exhibited adhesion to $\alpha 4 \beta 7$ compared with control cells. Indeed, L929 cells transduced with a $\mathrm{CDH} 26$ expression vector showed increased adhesion to $\alpha 4 \beta 7$-coated wells compared with control cells, in contrast to bovine serum albumin (BSA)-coated wells, which did not support adhesion of either cell type (Figure $4 \mathrm{~b}$ ). Visualization of cellular binding revealed a marked increase of $\mathrm{CDH} 26$-expressing cells binding $\alpha 4 \beta 7$ (Figure $4 c$ ). To further prove that $\mathrm{CDH} 26$ could directly bind $\alpha 4 \beta 7$, a solid-phase adhesion assay was performed in which recombinant CDH26-hIgG1-Fc (referred to as CDH26-Fc hereafter; see Supplementary Figure S3 and Supplementary Methods for details of isolation) was added to wells that were coated with recombinant $\alpha 4 \beta 7$. CDH26-Fc bound specifically to $\alpha 4 \beta 7$ and not BSA, whereas negative control IgG did not bind either $\alpha 4 \beta 7$ or BSA (Figure 4d). 
a

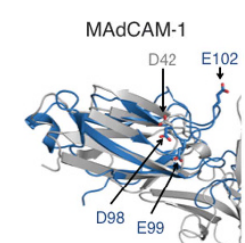

$\mathrm{CDH} 1$ (E-Cadherin)

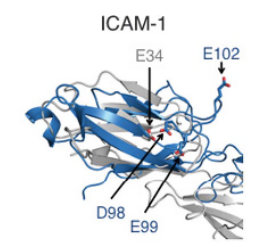

Fibronectin

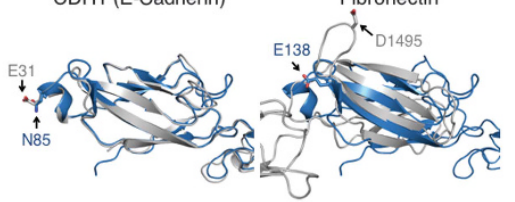

C

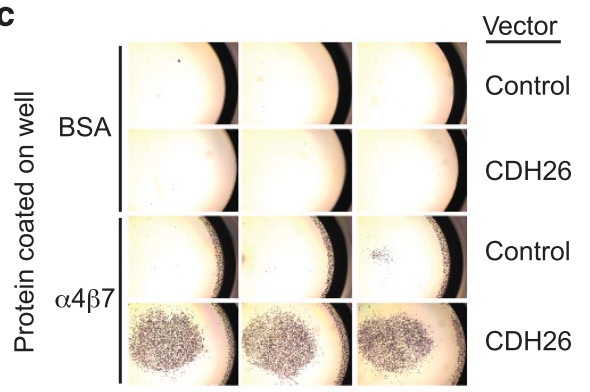

e

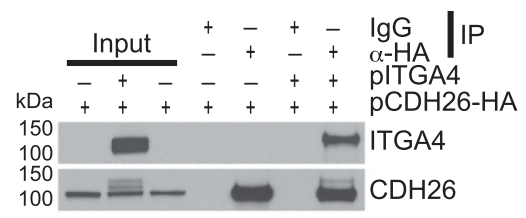

9
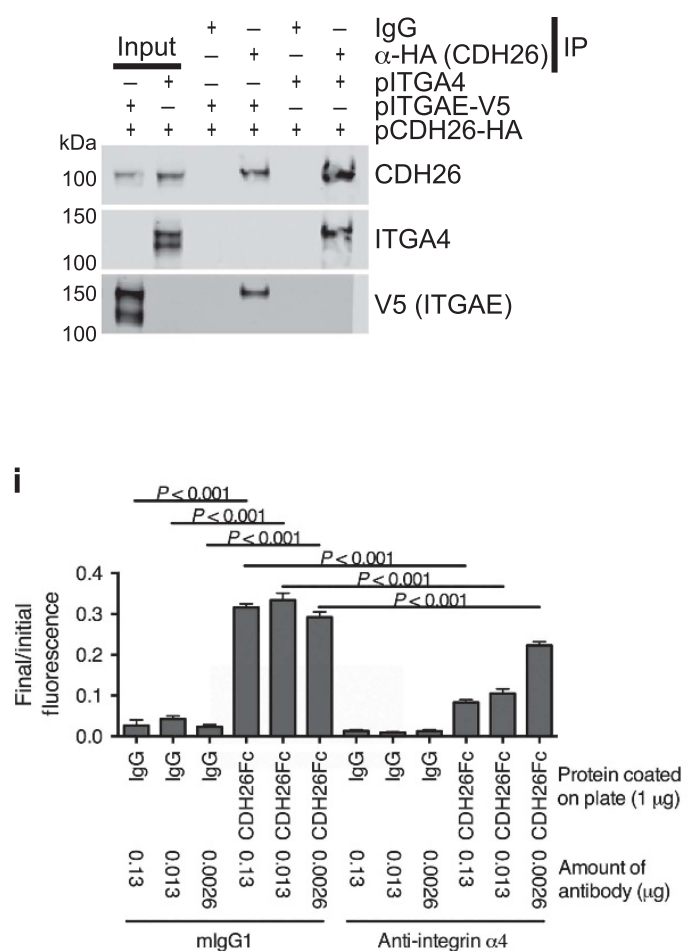

Figure 4 For caption see page 1196. b
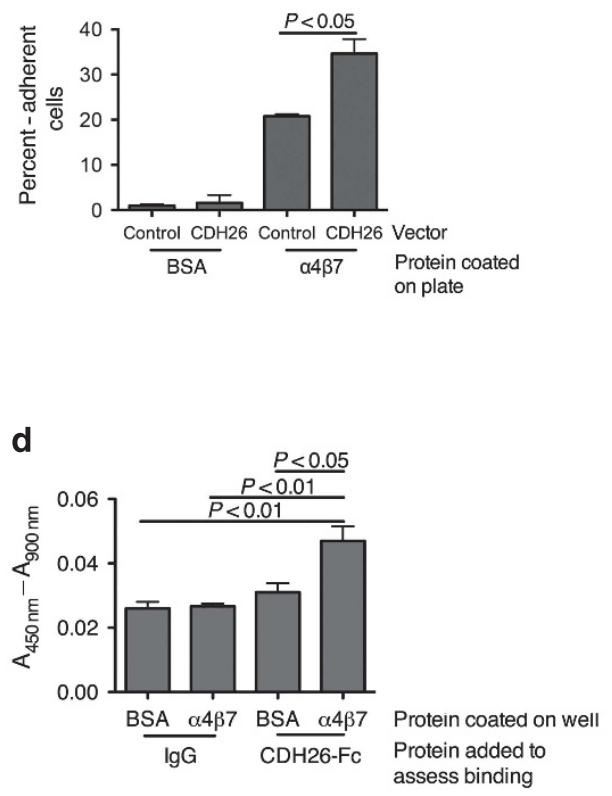

f

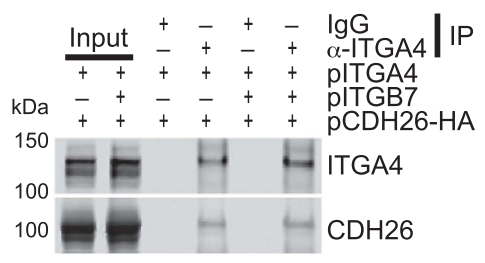

h

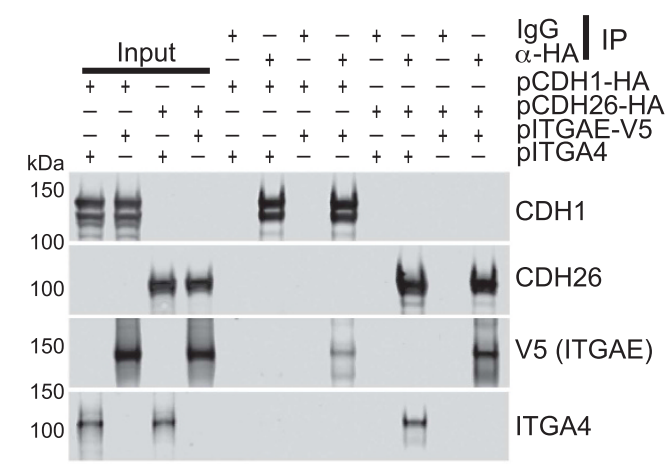

j

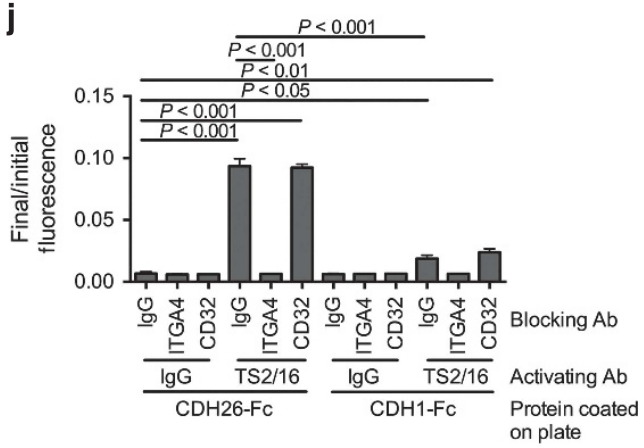


Figure 4 Binding of cadherin $26(\mathrm{CDH} 26)$ to integrins. (a) Pairwise structure alignment of CDH26 with known integrin ligands. CDH26 structure was modeled (blue) and aligned to the resolved structures of MAdCAM-1 (mucosal addressin cell adhesion molecule 1; PDB ID 1BQS), ICAM-1 (intercellular adhesion molecule 1; PDB ID 1IC1), CDH1 (PDB ID 1EDH), and fibronectin (PDB ID 1FNF) (gray). For each pair, integrin-binding amino acids and the corresponding $\mathrm{CDH} 26$ residues are labeled (arrows) and rendered using a stick representation. (b) Transduced L929 cell clones were dispersed and added to wells coated with either bovine serum albumin (BSA) or recombinant $\alpha 4 \beta 7$. The percentage of adherent cells remaining after wells were washed is shown. The graph represents seven experiments combined that each involved separate control and CDH26-overexpressing clones. (c) Pictures of Giemsa-stained wells from $\mathbf{b}$ were taken (original magnification, $\times 4$ ), with one control and one $\mathrm{CDH} 26$-overexpressing clone shown. (d) Wells were coated with or without recombinant $\alpha 4 \beta 7$ and then blocked with BSA, followed by addition of either hlgG1 or CDH26-hlgG1-Fc (CDH26-Fc). Bound antibody or fusion protein was then detected and expressed as $A_{450 \mathrm{~nm}}-A_{900 \mathrm{~nm}}$. Each condition was performed in triplicate. This graph shows one experiment representative of three. (e-h) Inputs (1/10 of amount used for immunoprecipitation) and immunoprecipitates from transiently transfected HEK 293T cells were subjected to sodium dodecyl sulfate-polyacrylamide gel electrophoresis and western blotting analysis. Each blot shown is representative of three independent experiments. (i, j) Fluorescently labeled Jurkat cells (untreated (i) or incubated with TS2/16 integrin $\beta 1$-activating antibodies (j)) preincubated with the indicated amount of control mlgG1, anti-integrin $\alpha 4$ (HP2/1), or anti-CD32 antibodies were added to wells coated with control hlgG1, CDH26-hlgG1-Fc (CDH26-Fc), or CDH1hlgG1-Fc (CDH1-Fc), as indicated. The graph indicates the percentage of fluorescence remaining after wells were washed. For $\mathbf{b}, \mathbf{d}$, $\mathbf{i}$, and $\mathbf{j}$, bars represent the mean, error bars represent the s.e.m, and data were analyzed by one-way analysis of variance followed by Tukey's posttest.

To further substantiate and address the specificity and molecular requirements for $\mathrm{CDH} 26 / \alpha 4 \beta 7$ interaction, overexpression and co-IP studies were carried out using HEK 293T cells. When HA-tagged CDH26 (CDH26-HA) and integrin $\alpha 4$ were overexpressed in HEK 293T cells, integrin $\alpha 4$ co-immunoprecipitated with $\mathrm{CDH} 26-\mathrm{HA}$ (Figure 4e), and the reciprocal was observed as $\mathrm{CDH} 26-\mathrm{HA}$ was found to co-immunoprecipitate with integrin $\alpha 4$ (Figure $4 \mathrm{f}$ ). In addition to integrin $\alpha 4$, V5-tagged integrin $\alpha \mathrm{E}$ (ITGAE-V5) was observed to co-immunoprecipitate with $\mathrm{CDH} 26-\mathrm{HA}$ (Figure 4g). Integrin $\alpha 4$ did not co-immunoprecipitate with $\mathrm{CDH} 1$, although positive control integrin $\alpha \mathrm{E}$ co-immunoprecipitated with CDH1 (Figure $4 \mathbf{h}$ ).

We next tested whether $\alpha 4$ bound to integrin $\beta 1$ could mediate interaction with $\mathrm{CDH} 26$ by observing whether cells that express integrin $\alpha 4 \beta 1$ adhered to recombinant $\mathrm{CDH} 26-\mathrm{Fc}$. Jurkat cells, which express integrin $\alpha 4 \beta 1$ but not $\alpha 4 \beta 7,{ }^{35}$ adhered to $\mathrm{CDH} 26$ Fc to a significantly greater degree than they adhered to IgG control antibody (Figure 4i). Preincubation of Jurkat cells with anti-integrin $\alpha 4$ antibody (HP2/1), but not an equivalent amount of control mIgG1, blocked their binding to $\mathrm{CDH} 26-\mathrm{Fc}$ in a dosedependent manner (Figure 4i). Jurkat cells stimulated with antibodies that activate integrin $\beta 1$ (clone TS2/16) adhered to $\mathrm{CDH} 26-\mathrm{Fc}$ in an integrin $\alpha 4$-dependent manner to a greater degree than they adhered to CDH1-Fc (Figure 4j).

\section{CDH26 modulates $\mathrm{CD}^{+}{ }^{+}$T-cell activation}

Because other $\alpha 4 \beta 1$ ligands, including VCAM-1 (vascular cell adhesion

molecule 1), have been shown to co-stimulate $\mathrm{CD} 4^{+} \mathrm{T}$-cell activation, ${ }^{36-38}$ we sought to test the hypothesis that the putative integrin $\alpha 4$ ligand $\mathrm{CDH} 26$ had this property. After human peripheral blood $\mathrm{CD}^{+}{ }^{+} \mathrm{T}$ cells isolated by negative selection (detailed in Supplementary Methods) were incubated for $48 \mathrm{~h}$ in the presence of plate-bound anti-CD3 antibodies (clone OKT3) to induce suboptimal stimulation of the T-cell receptor (TCR), an increased percentage of the cells expressed CD25 at the cell surface as assessed by flow cytometric analysis (detailed in Supplementary Methods). However, the presence of $\mathrm{CDH} 26-\mathrm{Fc}$, but not IgG control, inhibited the increase in percentage of cells expressing CD25 in a dose-dependent manner (Figure 5a; see Supplementary
Figure S4a). Likewise, production of the cytokine IL-2 was inhibited by $\mathrm{CDH} 26-\mathrm{Fc}$ in a dose-dependent manner in cells subjected to TCR stimulation (Figure 5b). A similar inhibition of IL-4 secretion and CD69 and CD154 surface expression were also observed (data not shown). We next tested whether this effect was specific to $\mathrm{CDH} 26-\mathrm{Fc}$ or whether other cadherin-Fc proteins mediated inhibition of T-cell activation. Both CDH26$\mathrm{Fc}$ and $\mathrm{CDH} 1-\mathrm{Fc}$ attenuated the increase of $\mathrm{CD} 25$ surface expression following TCR stimulation of $\mathrm{CD}^{+} \mathrm{T}$ cells (Figure 5c; see Supplementary Figure S4b). The inhibition of CD4 ${ }^{+}$T-cell activation by both cadherin-Fc constructs was also apparent at the level of cytokine secretion; cadherin-Fc constructs inhibited the secretion of IL-2 in response to TCR stimulation (Figure 5d).

\section{DISCUSSION}

Herein we have elucidated the properties of $\mathrm{CDH} 26$, identifying it as a functional $\mathrm{CDH}$ with unique features in that it is the only $\mathrm{CDH}$ family member significantly upregulated in human allergic GI tissue, where it localizes to epithelial cells in the inflamed esophagus and stomach. CDH26 mediates calciumdependent cell adhesion, dimerizes/multimerizes, and interacts with alpha-, beta-, and p120-catenins. $\mathrm{CDH} 26$ also has the ability to impact leukocyte migration and adhesion. Moreover, we present biochemical, molecular, and functional evidence that $\mathrm{CDH} 26$-integrin interactions impact cellular adhesion; specifically, integrins $\alpha 4$ and $\alpha \mathrm{E}$ co-immunoprecipitate with $\mathrm{CDH} 26$, recombinant $\mathrm{CDH} 26-\mathrm{Fc}$ binds recombinant $\alpha 4 \beta 7$, $\mathrm{CDH} 26$-expressing cells adhere to integrin $\alpha 4 \beta 7$, and Jurkat cells adhere to recombinant $\mathrm{CDH} 26-\mathrm{Fc}$ in a manner dependent on integrin $\alpha 4$ (see Figure 6 and see Supplementary Table S1 for summary and comparison to $\mathrm{CDH} 1$ ). Besides uncovering a novel role for this molecule, we present evidence that it can be exploited to generate a potential therapeutic as $\mathrm{CDH} 26-\mathrm{Fc}$ is an immunosuppressive molecule, at least in vitro. Taken together, we have identified a novel functional $\mathrm{CDH}$ regulated during allergic inflammation and determined that it binds $\alpha$ integrins and has immunomodulatory properties.

Given our observation that $\mathrm{CDH} 26$ interacts with not only integrin $\alpha 4$ but also integrin $\alpha \mathrm{E}$, it might have a function similar to E-cadherin to regulate localization or activation of leukocytes during allergic responses via interacting with leukocyte 
a
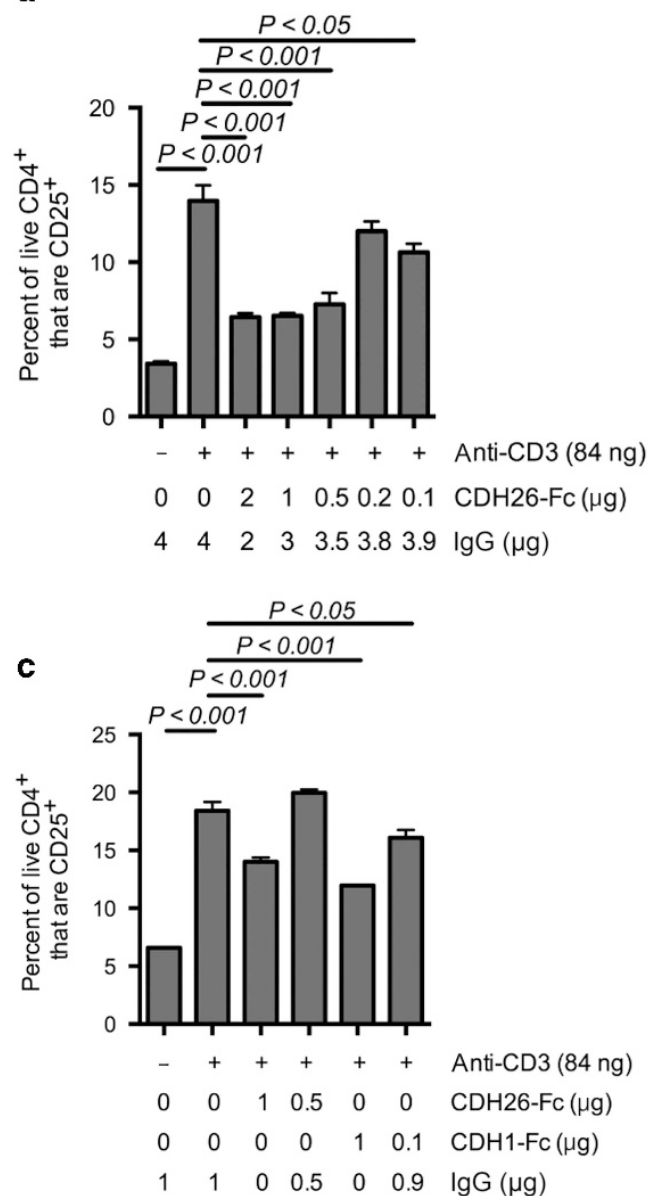

b

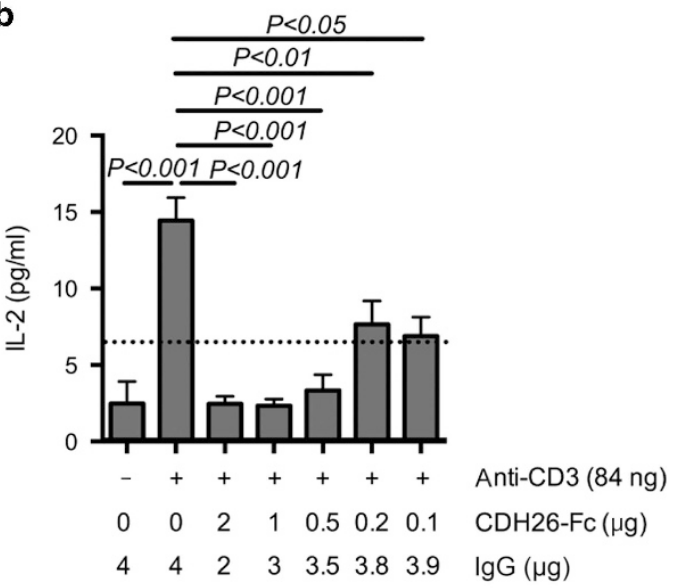

d

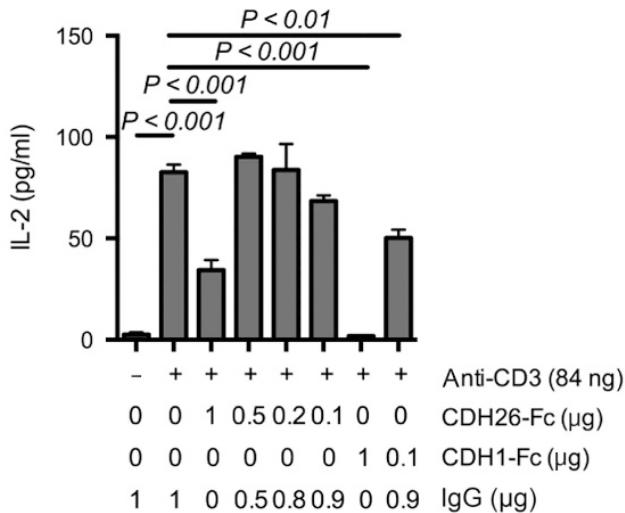

Figure 5 Effect of cadherin $26(\mathrm{CDH} 26)-\mathrm{Fc}$ and $\mathrm{CDH} 1-\mathrm{Fc}$ on $\mathrm{CD} 4^{+} \mathrm{T}$-cell activation. Human peripheral blood $\mathrm{CD} 4{ }^{+} \mathrm{T}_{\text {cells }}$ were isolated and cultured for $48 \mathrm{~h}$ in wells coated with the indicated amounts of proteins (IgG, anti-CD3, CDH26-Fc, and/or CDH1-Fc). Cells were stained for flow cytometric analysis to detect CD4 and CD25, and supernatants were analyzed to detect interleukin (IL)-2 levels by enzyme-linked immunosorbent assay (ELISA). For $\mathbf{a}$ and $\mathbf{c}$, the percentage of live $\mathrm{CD} 4^{+}$cells that are $\mathrm{CD} 25^{+}$are shown, and for (b and $\left.\mathbf{d}\right)$, the amount of IL-2 detected in the supernatant is shown. The dotted lines represent the detection limit for the ELISA. For (a to d), bars represent the mean, and error bars represent the s.e.m. Data were analyzed by one-way analysis of variance followed by Tukey's posttest. Data are results from one subject representative of those from five individual subjects for ( $\mathbf{a}$ and $\mathbf{b}$ ) and from one subject representative of those from four individual subjects for (c and $\mathbf{d})$.

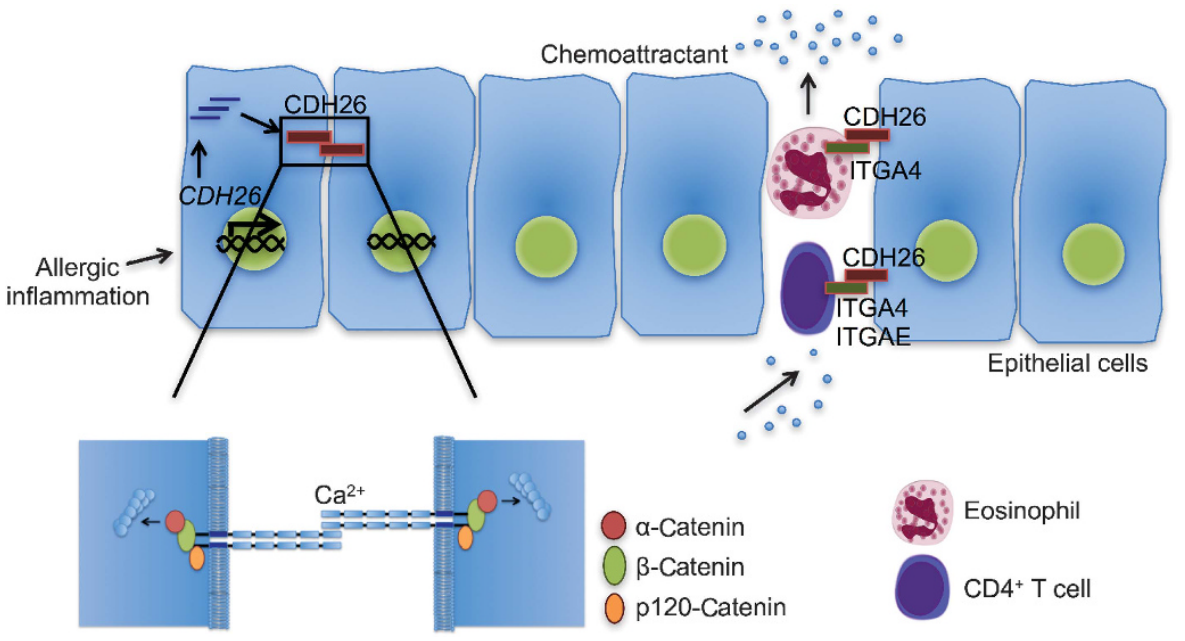

Figure 6 Model of cadherin $26(\mathrm{CDH} 26)$ expression and function in allergic inflammation. CDH26 is expressed by gastrointestinal (GI) epithelial cells in allergic GI inflammatory conditions. CDH26 dimerizes; interacts with beta-, alpha-, and p120-catenins; and mediates calcium-dependent cell adhesion. $\mathrm{CDH} 26$ additionally interacts with integrin $\alpha 4$ (ITGA4) and integrin $\alpha \mathrm{E}$ (ITGAE), which may impact leukocyte migration, localization, or activation status in allergic tissue. 
integrins. Epithelial $\mathrm{CDH} 26$ may impact the localization or activation status of diverse $\alpha 4^{+}$and/or $\alpha \mathrm{E}^{+}$cells (e.g., $\mathrm{CD} 4^{+} \mathrm{T}$ cells, eosinophils, mast cells) within the epithelium in the context of allergic inflammation. In particular, these subsets of cells are known to be increased in the esophageal epithelium of EoE patients compared with control patients; ${ }^{17,26,39}$ furthermore, numerous intraepithelial eosinophils are observed in EoE and EG but not in normal esophageal or gastric tissue. This altered intraepithelial localization of several subsets of cells correlates with the fact that $\mathrm{CDH} 26$ appears to be a highly inducible molecule in epithelial cells that is present at only low levels under homeostatic conditions.

We identified several lines of evidence that $\mathrm{CDH} 26$ interacts with alpha integrins and facilitates cellular binding to $\alpha 4$-containing integrins, including both integrin $\alpha 4 \beta 7$ and $\alpha 4 \beta 1$. Biochemical assays suggested that the extracellular portion of $\mathrm{CDH} 26$ could directly bind the $\alpha 4$-containing integrin $\alpha 4 \beta 7$. Furthermore, we observed that cells expressing high levels of $\mathrm{CDH} 26$ adhered to recombinant integrin, and in the reciprocal situation, recombinant $\mathrm{CDH} 26$ was sufficient to mediate adhesion of Jurkat $\mathrm{T}$ cells in a manner dependent on integrin $\alpha 4$. Such interactions are consistent with the structural properties of $\mathrm{CDH} 26$, which include the presence of solventexposed acidic residues that could be critical to facilitate the $\mathrm{CDH} 26 /$ integrin interaction. We speculate that, in addition to mediating adhesion, interaction of epithelial-expressed CDH26 with leukocyte integrins could initiate intracellular signaling in both epithelial cells and leukocytes. This could impact diverse processes, such as alteration of gene expression, regulation of barrier function, or production of mediators by either cell type.

It has been shown that integrin $\alpha 4$ ligands, including fibronectin, VCAM-1, and MAdCAM- 1 , costimulate CD4 ${ }^{+}$T cells activated by suboptimal TCR activation. ${ }^{36-38}$ Our data show that $\mathrm{CDH} 26-\mathrm{Fc}$ inhibited $\mathrm{CD}^{+}{ }^{+}$T-cell activation mediated by suboptimal TCR engagement. We additionally observed that $\mathrm{CDH} 1-\mathrm{Fc}$ had similar effects. In fact, although $\mathrm{CDH} 1$ has previously been shown to co-stimulate $\mathrm{CD} 4{ }^{+} \mathrm{T}$-cell activation, ${ }^{40}$ it has additionally been shown to be an inhibitory molecule in several settings; for example, ligation of E-cadherin expressed by dendritic epidermal T cells with $\mathrm{CDH} 1$ expressed by epidermal keratinocytes inhibits dendritic epidermal T-cell interferon- $\gamma$ production, tumor necrosis factor- $\alpha$ production, and degranulation in response to TCR stimulation. ${ }^{14}$ Moreover, $\mathrm{CDH} 1$ has been shown to be a counter-receptor for killer cell lectin-like receptor G1 (KLRG1), which is expressed by natural killer cells, memory T cells, and type 2 innate lymphoid cells. Engagement of KLRG1 by E-cadherin promotes inhibitory effects in the KLRG1-expressing cell, including inhibition of natural killer cell cytotoxicity, inhibition of antigeninduced proliferation, and induction of cytolytic activity of $\mathrm{CD}^{+}{ }^{+} \mathrm{T}$ cells, and inhibition of type 2 cytokine production of type 2 innate lymphoid cells. ${ }^{41-43}$ We speculate that $\mathrm{CDH} 26$ may act as a counter-regulatory molecule either through engagement of integrins or other unknown counter-receptors to dampen the Th2-associated inflammatory responses. Although molecules upregulated during disease might be assumed to be involved in promoting disease, upregulation of $\mathrm{CDH} 26$ could be part of the mechanism by which resolution of inflammation occurs to promote the return of the tissue to homeostasis. Alternatively, it is possible that $\mathrm{CDH} 26$ engagement may inhibit particular subsets of $\mathrm{CD} 4^{+} \mathrm{T}$ cells: for example, regulatory $\mathrm{T}$ cells, which are known to be increased in EoE and EG ${ }^{16,20,44}$ or other more select CD4 ${ }^{+}$T-cell subsets such as Th1 or Th2 cells. Depending on the subset of T cells inhibited, the molecule could serve either to dampen or accelerate Th2-associated inflammatory responses. In summary, $\mathrm{CDH} 26$ is now the second $\mathrm{CDH}$ (besides $\mathrm{CDH} 1$ ) that has been shown to bind $\alpha$-integrins, extending the paradigm of $\mathrm{CDH} /$ integrin interactions and leading to the unexpected finding that $\mathrm{CDH} 26-$ $\mathrm{Fc}$ (as well as $\mathrm{CDH} 1-\mathrm{Fc}$ ) has T-cell immunosuppressive activity, providing a potential novel therapeutic strategy.

\section{METHODS}

Methods related to patient studies, expression constructs, cell isolation, fluorescence-activated cell sorting analysis, enzyme-linked immunosorbent assay (ELISA), and bioinformatics analysis can be found in Supplementary Material.

\section{Quantitation of transcript levels}

Microarray analysis. For microarray analysis, biopsy samples collected during the index endoscopy were stored in RNAlater until subjected to RNA isolation using the miRNeasy Kit (Qiagen, Germantown, MD) per the manufacturer's instructions. RNA labeling and hybridization to the GeneChip Human Genome U133 Plus 2.0 Array (Affymetrix, Santa Clara, CA) was performed as reported. ${ }^{26}$ RNA labeling, hybridization, and generation of expression data were performed by the Gene Expression Microarray Core at Cincinnati Children's Hospital Medical Center (CCHMC), Cincinnati, Ohio, USA. In some cases, the raw signal intensity of particular probe sets was reported. Transcripts for which all individual samples exhibited a raw signal of $\leqslant 100$ were considered to be not expressed. Transcripts with raw signal $\geqslant 400$ were considered to be substantially expressed.

Quantitative PCR. Total RNA (100 ng-1 $\mu \mathrm{g})$ isolated from biopsy specimens using the miRNeasy Kit (Qiagen) or from cells using Trizol (Invitrogen, Waltham, MA) was used to synthesize cDNA using Superscript II Reverse Transcriptase (Invitrogen). Real-time PCR was performed using the iQ5 system (Bio-Rad, Hercules, CA) and SYBR green mix (Bio-Rad). The value obtained for each primer set (see Supplementary Table S3) was normalized to the GAPDH value for the corresponding sample.

\section{Protein and cell detection in tissue}

Histopathology. Biopsies for histological evaluation were fixed in $10 \%$ formalin, routinely processed, and embedded in paraffin. Sections $(5 \mu \mathrm{m})$ were stained with hematoxylin and eosin or with specific antibodies. Immunohistochemical stains were performed using Ventana Benchmark XT automated immunostainer. Antigen retrieval (EDTA, $30 \mathrm{~min}$ ) was followed by staining with anti-CDH26 (1:50, Sigma-Aldrich, St. Louis, MO) or anti-H. pylori (Ventana Medical Systems, Tuscon, AZ) antibodies. For quantitative microscopy, multiple levels of biopsies were surveyed, and the areas containing the greatest concentration of eosinophils or immunopositive cells were identified and enumerated at $\times 400\left(0.3 \mathrm{~mm}^{2}\right)$ to generate a peak count per biopsy. Quantitative evaluations were performed in well-oriented areas when feasible.

\section{Cell culture and manipulation}

Culture of cell lines and cytokine treatment. Human esophageal squamous epithelial cancer cell line TE-7 was kindly provided by $\mathrm{Dr}$ Hainault (IARC, Lyon, France). These cells were maintained in RPMI medium (Invitrogen) supplemented with $5 \%$ fetal bovine serum (FBS; 
Atlanta Biologicals, Flowery Branch, GA) and 1\% penicillin/streptomycin (Invitrogen). HEK 293T cells and L929 cells were grown in Dulbecco's modified Eagle's medium (DMEM; Invitrogen) supplemented with 10\% FBS (Atlanta Biologicals) and 1\% penicillin/ streptomycin (Invitrogen). Jurkat cells were cultured in RPMI medium (Invitrogen) supplemented with 10\% FBS (Atlanta Biologicals) and 1\% penicillin/streptomycin (Invitrogen).

Lentivirus production and transduction of HEK 293T, TE-7, and L929 cells. For pMIRNA1 constructs, lentivirus production was carried out by the CCHMC Viral Vector Core. HEK 293T, TE-7, and L929 cells were transduced by incubating lentivirus with the cells for $24 \mathrm{~h}$ in the presence of $5 \mu \mathrm{g} \mathrm{ml}^{-1}$ polybrene. Media were then changed, and after $24 \mathrm{~h}$, medium containing $2 \mu \mathrm{g} \mathrm{ml}^{-1}$ puromycin was added. After selection for $48 \mathrm{~h}$ in puromycin, cells were dispersed and plated to single cells in 96-well plates to obtain clones derived from single cells. A second round of dispersing, plating to single cells, and picking single colonies was performed. CDH26 expression was verified by western blotting analysis.

\section{Protein methods}

Protein extracts and IP. Cell lysates were prepared from HEK 293T cells generally as described. Cells (approximately $2 \times 10^{6}$ ) were washed one time with phosphate-buffered saline and incubated in IP buffer (50 mм Tris- $\mathrm{HCl}$ ( $\mathrm{pH} 7.4$ ), $150 \mathrm{~mm} \mathrm{NaCl}, 2 \mathrm{~mm}$ EDTA, $1 \mathrm{~mm}$ dithiothreitol, $1 \%$ Nonidet P-40 (NP-40); or $10 \mathrm{~mm}$ imidazole, $100 \mathrm{~mm} \mathrm{NaCl}, 1 \mathrm{~mm} \mathrm{MgCl}, 5 \mathrm{~mm}$ EDTA, $1 \%$ Triton X-100, pH 7.4) containing $1 \times$ complete protease inhibitor cocktail (Roche) for $10 \mathrm{~min}$ on ice. Cells were scraped from the plate and rotated at $4{ }^{\circ} \mathrm{C}$ for $10 \mathrm{~min}$. Lysates were cleared by centrifugation at $20,000 \mathrm{~g}$ at $4{ }^{\circ} \mathrm{C}$ for $10 \mathrm{~min}$. An equal amount of protein was added to total $500 \mu \mathrm{l}$ of IP buffer plus protease inhibitors (Roche). Antibodies (2 $\mu \mathrm{g} \alpha$-HA (Covance, Princeton, NJ), $\alpha$-myc (Covance), $\alpha$-p120 (BD Transduction Laboratories, San Jose, CA), $\alpha$-ITGA4 (Cell Signaling Technology, Danvers, MA), mouse IgG1 control (AbD Serotec, Hercules, CA), or normal rabbit IgG control (R\&D Systems, Minneapolis, MN)) were added and rotated overnight at $4{ }^{\circ} \mathrm{C}$. Subsequently, $20 \mu \mathrm{l}$ of protein A/ $\mathrm{G}$ agarose beads (Santa Cruz Biotechnology, Dallas, TX) were added per sample. After $2 \mathrm{~h}$ of rotation $\left(4^{\circ} \mathrm{C}\right)$, beads were washed five times in IP buffer containing protease inhibitors. In all, $2 \times$ Laemmli buffer was added to the immunoprecipitates or total cell lysates saved prior to IP (input).

Biopsy protein extracts. Distal esophagus or gastric antrum biopsy specimens were transferred into $100 \mu \mathrm{l}$ of IP buffer $(50 \mathrm{~mm}$ Tris- $\mathrm{HCl}$ ( $\mathrm{pH}$ 7.4), $150 \mathrm{~mm} \mathrm{NaCl}, 2$ mм EDTA, 1 mm dithiothreitol, $1 \%$ Nonidet P-40 (NP-40), $1 \times$ protease inhibitors (Roche)) and sonicated. Lysates were cleared by centrifugation $\left(20,000 \mathrm{~g}, 4^{\circ} \mathrm{C}, 10 \mathrm{~min}\right)$. Alternatively, protein was isolated from the organic fraction remaining after RNA isolation from biopsy specimens using the miRNeasy Kit (Qiagen). DNA was precipitated by the addition of 0.3 volumes of ethanol followed by a $2,000 \mathrm{~g}$ spin. Protein was precipitated from the supernatant by addition of three volumes of acetone, pelleted by centrifugation $\left(20,000 \mathrm{~g}, 10 \mathrm{~min}, 4^{\circ} \mathrm{C}\right)$, dried, and solubilized in Laemmli buffer $(2 \times)$.

Biotinylation of cell surface proteins. Adherent cells were washed with ice-cold biotinylation buffer (100 mm HEPES, $50 \mathrm{~mm} \mathrm{NaCl}, \mathrm{pH} 8.0$ ) twice; cold biotinylation buffer plus sulfo-NHS-LC-biotin $\left(0.9259 \mathrm{mg} \mathrm{ml}^{-1}\right)$ (Thermo Scientific) was then added $(30 \mathrm{~min}$ on ice). Buffer was removed, cells were washed three times with ice-cold phosphate-buffered saline with $100 \mathrm{~mm}$ glycine, and protein was then extracted as described above using IP buffer with protease inhibitors. Cell lysates were incubated with streptavidin-agarose beads (SigmaAldrich) for $2 \mathrm{~h}$ at $4{ }^{\circ} \mathrm{C}$. Beads were washed five times with cold IP buffer containing $1 \mathrm{~mm}$ PMSF followed by addition of $2 \times$ Laemmli buffer.

SDS-PAGE and western blotting analysis. Total protein, inputs, or immunoprecipitates were loaded onto either $4-12 \%$ NuPage Tris-bis gels (Invitrogen) and electrophoresed for $1.5 \mathrm{~h}$ at $150 \mathrm{~V}$ or $4-12 \%$ BOLT gels (Invitrogen) and electrophoresed for $50 \mathrm{~min}$ at $165 \mathrm{~V}$. Proteins were then transferred to nitrocellulose membranes. Primary antibodies were diluted in TBS $/ 0.1 \%$ Tween 20 containing $5 \%$ milk or Odyssey blocking buffer (LI-COR Biosciences, Lincoln, NE) $+0.2 \%$ Tween 20: rabbit anti-CDH26 (Sigma-Aldrich), 1:500; rabbit antibeta-catenin (Cell Signaling Technology), 1:1,000; mouse anti-p120 (BD Transduction Laboratories), 1:1,000; mouse anti-HA (Covance), 1:1,000; rabbit anti-HA (Santa Cruz Biotechnology), 1:200; mouse anti-Myc (Cell Signaling Technology), 1:1,000; mouse anti-beta-actin (Sigma-Aldrich), 1:1,000; rabbit anti-V5 (Bethyl Laboratories), 1:1,000; rabbit anti-ITGA4 (Cell Signaling Technology), 1:1,000; and rabbit anti-E-cadherin (Cell Signaling Technology), 1:1,000. Horseradish peroxidase (HRP)-conjugated secondary antibodies were incubated with the membranes in TBS/ $0.1 \%$ Tween 20 containing 5\% milk: anti-rabbit HRP, 1:10,000 (Cell Signaling Technology); antimouse HRP, 1:10,000 (Cell Signaling Technology). Blottings were developed using ECL Plus reagent (GE Healthcare, Chicago, IL). Densitometry measurements were performed using Multi Gauge V3.0 (Fugifilm, Valhalla, NY). Alternatively, secondary antibodies conjugated to infrared fluorophores (anti-rabbit IRDye $800 \mathrm{CW}$ or antimouse IRDye 680RD; 1:15,000) (LI-COR Biosciences) were used, and blotting was carried out in a similar manner except that antibodies were diluted in Odyssey blocking buffer (LI-COR Biosciences) $+0.2 \%$ Tween 20 and infrared signal was visualized and quantified using the Odyssey CLx Infrared Imaging System and ImageStudio software (LICOR Biosciences).

Solid phase adhesion assay. Recombinant human integrin $\alpha 4 \beta 7$ (R\&D Systems) was diluted to the indicated concentration in buffer $(150 \mathrm{mM}$ $\mathrm{NaCl}, 20 \mathrm{~mm}$ HEPES); $100 \mu \mathrm{l}$ per well was added to Costar half-well ELISA plates (Corning, Corning, NY) and incubated overnight at $4{ }^{\circ} \mathrm{C}$. The following day, wells were washed and blocked with 5\% BSA in buffer (150 mM NaCl, $20 \mathrm{~mm}$ HEPES) overnight at $4{ }^{\circ} \mathrm{C}$. The following day, the wells were washed, and IgG1 or CDH26-hIgG1-Fc diluted in assay buffer (150 mM NaCl, $20 \mathrm{~mm}$ HEPES, $1 \mathrm{~mm} \mathrm{CaCl}, 1 \mathrm{~mm} \mathrm{MgCl}_{2}$, $1 \mathrm{~mm} \mathrm{MnCl}_{2}$ ) containing 5\% BSA was added to wells for $60 \mathrm{~min}$ at $37^{\circ} \mathrm{C}$. Wells were washed $3 \times$, and detection antibody (biotinylated anti-human IgG1 (Vector Laboratories, Burlingame, CA); $0.5 \mu \mathrm{g} \mathrm{ml}^{-1}$ in assay buffer with $5 \% \mathrm{BSA}$ ) was added for $2 \mathrm{~h}$ at room temperature. Wells were washed $3 \times$ with assay buffer with 5\% BSA, and streptavidin-HRP was added (1:200 in assay buffer with 5\% BSA; $\mathrm{R} \& \mathrm{D}$ Systems). Wells were washed $3 \times$ with assay buffer with $5 \% \mathrm{BSA}$, and a 1:1 dilution of TMB substrate (BD Biosciences, San Jose, CA) was added. The reaction was stopped by the addition of $2 \mathrm{~N} \mathrm{H}_{2} \mathrm{SO}_{4}$. Absorbance at 450 and $900 \mathrm{~nm}$ was measured using a plate reader (BioTek, Winooski, VT).

\section{Functional assays}

Aggregation assay. L929 cells were treated with DMEM containing $0.1 \%$ trypsin at a final concentration of $5 \mathrm{~mm} \mathrm{CaCl}_{2}\left(30 \mathrm{~min}, 37^{\circ} \mathrm{C}\right)$. Cells were washed once with DMEM containing $10 \%$ FBS and then twice with $1 \times$ HBSS containing $1 \%$ FBS. Cells were counted, and $2 \times 10^{6}$ cells were aliquoted into $1.5-\mathrm{ml}$ tubes (two tubes per cell type). Cells were spun down and resuspended in HEPES-buffered magnesium-free saline (10 mM HEPES in saline) that either contained or lacked $1 \mathrm{~mm} \mathrm{CaCl}_{2}$. The initial particle number was counted, and then tubes were rotated at $37^{\circ} \mathrm{C}$ for $30 \mathrm{~min}$. The final particle number was then counted. The aggregation index was expressed as ((initial particle number - final particle number)/initial particle number).

Cell adhesion to recombinant integrin assay. Recombinant human $\alpha 4 \beta 7$ (R\&D Systems) was diluted to the indicated concentration in buffer ( $150 \mathrm{~mm} \mathrm{NaCl}, 20 \mathrm{~mm}$ HEPES), and $100 \mu \mathrm{l}$ per well was added to half-well Costar ELISA plates (Corning) and incubated overnight at $4{ }^{\circ} \mathrm{C}$. The following day, wells were washed and coated with 5\% BSA in buffer ( $150 \mathrm{~mm} \mathrm{NaCl}, 20 \mathrm{~mm}$ HEPES) $\left(3 \mathrm{~h}, 37^{\circ} \mathrm{C}\right)$. L929 cell clones transduced with the indicated construct and grown to confluency were then dispersed and resuspended in assay buffer ( $150 \mathrm{~mm} \mathrm{NaCl}, 20 \mathrm{~mm}$ 
HEPES, $1 \mathrm{~mm} \mathrm{CaCl}_{2}, 1 \mathrm{~mm} \mathrm{MgCl}_{2}, 1 \mathrm{~mm} \mathrm{MnCl}_{2}$ ). For each cell type, 50,000 cells were added per well. The plate was spun at $10 \mathrm{~g}$ for $1 \mathrm{~min}$ and subsequently incubated at $37^{\circ} \mathrm{C}$ for $1 \mathrm{~h}$. Wells were washed by gravity one time by inverting the plate in a large beaker of assay buffer for $10 \mathrm{~min}$. Two additional washes were performed by pipetting $100 \mu \mathrm{l}$ of assay buffer into the wells four times per wash. Fluorescence was measured prior to the washes and after each wash using a plate reader (ex/em 485/20 nm/528/20 nm) (BioTek). The results are expressed as the percentage of fluorescence remaining (fluorescence after the last wash/initial fluorescence) for each well.

Cell adhesion assay. CDH26-hIgG1-Fc, CDH1-Fc (R\&D Systems), and/or hIgG1 (Southern Biotech, Birmingham, AL) were diluted in buffer (150 mм NaCl, $20 \mathrm{~mm}$ HEPES) to appropriate concentrations so that the indicated amount of protein was added to Costar half-well ELISA plates in $50 \mu \mathrm{l}$ per well (Corning) and incubated overnight at $4{ }^{\circ} \mathrm{C}$. The next day, Jurkat cells $\left(1 \times 10^{6} \mathrm{ml}^{-1}\right)$ were incubated in HEPES medium (132 mM NaCl, $6 \mathrm{~mm} \mathrm{KCl,} 1 \mathrm{~mm} \mathrm{CaCl}_{2}, 1 \mathrm{~mm} \mathrm{MgSO}_{4}$, $1.2 \mathrm{mM} \mathrm{KH}_{2} \mathrm{PO}_{4}, 20 \mathrm{~mm}$ HEPES, $5.5 \mathrm{~mm}$ glucose, $0.5 \%$ BSA) plus $4 \mu \mathrm{g} \mathrm{ml}^{-1}$ calcein-AM (Sigma-Aldrich) for $1 \mathrm{~h}$ at $37^{\circ} \mathrm{C}$. Cells were washed $3 \times$ in HEPES medium. In the indicated cases, cells were incubated with $1.4 \mu \mathrm{g}$ of either anti-integrin $\beta 1$-activating antibodies (clone TS2/16, Santa Cruz Biotechnology) or an equivalent amount of mIgG1 (Southern Biotech). In the indicated cases, labeled cells were then preincubated with the indicated amount of either mIgG1 (AbD Serotec), anti-integrin $\alpha 4$ (HP2/1; AbD Serotec), or anti-CD32 (Stem Cell Technologies, Vancouver, BC, Canada) antibodies in assay buffer for non-TS2/16-treated cells ( $150 \mathrm{~mm} \mathrm{NaCl}, 10 \mathrm{~mm}$ HEPES, $1 \mathrm{~mm}$ $\mathrm{CaCl}_{2}, 1 \mathrm{~mm} \mathrm{MgCl}_{2}, 1 \mathrm{~mm} \mathrm{MnCl}_{2}$ ) or HEPES medium for TS2/16treated cells for $15 \mathrm{~min}$ at $4{ }^{\circ} \mathrm{C}$ prior to their addition to wells $(50,000$ cells per well). Plates were spun at $10 \mathrm{~g}$ for $1 \mathrm{~min}$ and then incubated at $37^{\circ} \mathrm{C}$ for $45 \mathrm{~min}$. Initial fluorescence per well was then measured using a plate reader ((ex/em 360/40 nm/460/40 nm); BioTek). Wells were washed by gravity one time by inverting the plate in a large beaker of assay buffer for $10 \mathrm{~min}$. Two additional washes were performed by pipetting $100 \mu \mathrm{l}$ of assay buffer into the wells four times per wash. Final fluorescence was then measured.

$\mathrm{CD}^{+}{ }^{+}$T-cell activation assay. The indicated amounts of anti-CD3 (clone OKT3, eBioscience, San Diego, CA) antibodies, CDH26-hIgG1FC, CDH1-Fc (R\&D Systems), and/or hIgG1 control antibody (Southern Biotech) were suspended in coating buffer (20 mM HEPES, $150 \mathrm{~mm} \mathrm{NaCl}$ ), added to wells of a 96-well cell culture plate, and incubated overnight at $4{ }^{\circ} \mathrm{C}$. The following day, isolated human peripheral blood CD4 ${ }^{+}$T cells $(150,000$ per well) were added to the wells in RPMI supplemented with $10 \%$ FBS, $1 \%$ penicillin/streptomycin, and $200 \mathrm{~mm}$ glutamine. Cells were incubated for $48 \mathrm{~h}$. Cells and supernatants were then collected for analysis by flow cytometry and ELISA, respectively.

Statistics. Data are expressed as mean \pm s.e.m. or media$\mathrm{n} \pm$ interquartile range. Statistical significance was determined using unpaired $t$-test (2 groups, normal distribution, equal variance), MannWhitney test (2 groups, nonparametric), one-way analysis of variance followed by the Tukey's posttest ( $>2$ groups), or the Kruskal-Wallis test followed by Dunn's multiple comparison test ( $>2$ groups, nonparametric) with the Prism 5.0 software (GraphPad Software, La Jolla, CA).

SUPPLEMENTARY MATERIAL is linked to the online version of the paper at http://www.nature.com/mi

\section{ACKNOWLEDGMENTS}

We thank the CCED and clinical research coordinators for facilitating patient sample and data collection; Michael Eby for EGID database maintenance, queries, and retrieval of patient information; the Cincinnati Digestive Health Center Integrative Morphology Core for tissue processing, sectioning, histology, and immunohistochemical staining; Betsy DiPasquale for assistance with immunohistochemical stains; Dr Andrew Herr for advice regarding protein expression and purification; Dr Bruce Bochner for critical review of the manuscript; and physicians who collected biopsy samples, including Dr James Franciosi, Dr Kathleen Campbell, Dr Michael Farrell, Dr Ajay Kaul, and Dr Gitit Tomer. This work was supported in part by NIH U19 Al070235, NIH R01 DK076893, the PHS Grant P30 DK0789392, American Heart Association 11POST440046, the Sunshine Charitable Foundation and its supporters, Denise A. Bunning and David G. Bunning, the Buckeye Foundation, and the Campaign Urging Research for Eosinophilic Diseases (CURED) Foundation.

\section{AUTHOR CONTRIBUTIONS}

J.M.C. and M.H.C. designed and performed experiments, analyzed data, and wrote the paper; K.A.K. performed tissue sample processing and performed experiments; J.D.S., T.W., M.R., L.A., and H.T. designed and performed experiments and analyzed data; M.J.D., M.R.W., and A.P. performed protein structure and bioinformatics analyses and gave conceptual advice; E.M.S. performed tissue sample processing and assisted in acquiring clinical information; P.E.P. collected patient tissue; J.P.A. acquired clinical information and gave conceptual advice; M.E.R designed the study, analyzed data, and wrote the paper.

\section{DISCLOSURE}

M.E.R. is a consultant for Receptos, Pulm-One, and NKT Therapeutics and has an equity interest in Immune Pharmaceuticals, Pulm-One, and NKT Therapeutics and royalties in reslizumab (Teva Pharmaceuticals). M.H.C. is a consultant for Meritage Pharma, Novartis, Receptos, Regeneron, and Aptalis. J.M.C. and M.E.R. are co-inventors of patents and/or applications, owned by Cincinnati Children's Hospital, concerning some of the data in this paper. The other authors declared no conflict of interest.

c) 2017 Society for Mucosal Immunology

\section{REFERENCES}

1. Shimoyama, Y. et al. Cadherin cell-adhesion molecules in human epithelial tissues and carcinomas. Cancer Res. 49, 2128-2133 (1989).

2. Wheelock, M.J., Shintani, Y., Maeda, M., Fukumoto, Y. \& Johnson, K.R. Cadherin switching. J. Cell. Sci. 121 (Pt 6), 727-735 (2008).

3. Gassler, N. et al. Inflammatory bowel disease is associated with changes of enterocytic junctions. Am. J. Physiol. Gastrointest. Liver Physiol. 281, G216-G228 (2001)

4. Heijink, I.H., Nawijn, M.C. \& Hackett, T.L. Airway epithelial barrier function regulates the pathogenesis of allergic asthma. Clin. Exp. Allergy 44, 620-630 (2014).

5. Hupin, C., Gohy, S., Bouzin, C., Lecocq, M., Polette, M. \& Pilette, C. Features of mesenchymal transition in the airway epithelium from chronic rhinosinusitis. Allergy 69, 1540-1549 (2014).

6. Trautmann, A. et al. The differential fate of cadherins during T-cell-induced keratinocyte apoptosis leads to spongiosis in eczematous dermatitis. J. Invest. Dermatol. 117, 927-934 (2001).

7. Valencia, X. et al. Cadherin-11 provides specific cellular adhesion between fibroblast-like synoviocytes. J. Exp. Med. 200, 1673-1679 (2004).

8. Trautmann, A. et al. Apoptosis and loss of adhesion of bronchial epithelial cells in asthma. Int. Arch. Allergy Immunol. 138, 142-150 (2005).

9. de Boer, W.I., Sharma, H.S., Baelemans, S.M., Hoogsteden, H.C., Lambrecht, B.N. \& Braunstahl, G.J. Altered expression of epithelial junctional proteins in atopic asthma: possible role in inflammation. Can. J. Physiol. Pharmacol. 86, 105-112 (2008).

10. Heijink, I.H., Kies, P.M., Kauffman, H.F., Postma, D.S., van Oosterhout, A.J. \& Vellenga, E. Down-regulation of E-cadherin in human bronchial epithelial cells leads to epidermal growth factor receptor-dependent Th2 cell-promoting activity. J. Immunol. 178, 7678-7685 (2007).

11. Cepek, K.L., Parker, C.M., Madara, J.L. \& Brenner, M.B. Integrin alpha E beta 7 mediates adhesion of T lymphocytes to epithelial cells. J. Immunol. 150 (8 Pt 1), 3459-3470 (1993).

12. Cepek, K.L. et al. Adhesion between epithelial cells and T lymphocytes mediated by E-cadherin and the alpha E beta 7 integrin. Nature 372, 190-193 (1994). 
13. Schon, M.P. et al. Mucosal T lymphocyte numbers are selectively reduced in integrin alpha E (CD103)-deficient mice. J. Immunol. 162, 6641-6649 (1999).

14. Uchida, Y., Kawai, K., Ibusuki, A. \& Kanekura, T. Role for E-cadherin as an inhibitory receptor on epidermal gammadelta T cells. J. Immunol. 186, 6945-6954 (2011).

15. Teitelbaum, J.E. et al. Eosinophilic esophagitis in children: immunopathological analysis and response to fluticasone propionate. Gastroenterology 122, 1216-1225 (2002).

16. Tantibhaedhyangkul, U., Tatevian, N., Gilger, M.A., Major, A.M. \& Davis, C.M. Increased esophageal regulatory T cells and eosinophil characteristics in children with eosinophilic esophagitis and gastroesophageal reflux disease. Ann. Clin. Lab. Sci. 39, 99-107 (2009).

17. Lucendo, A.J. etal. Immunophenotypic characterization and quantification of the epithelial inflammatory infiltrate in eosinophilic esophagitis through stereology: an analysis of the cellular mechanisms of the disease and the immunologic capacity of the esophagus. Am. J. Surg. Pathol. 31, 598-606 (2007).

18. Doherty, T.A. et al. Group 2 innate lymphocytes (ILC2) are enriched in active eosinophilic esophagitis. J. Allergy Clin. Immunol. 136, 792-794 e793 (2015).

19. Blanchard, C. et al. IL-13 involvement in eosinophilic esophagitis: transcriptome analysis and reversibility with glucocorticoids. J. Allergy Clin. Immunol. 120, 1292-1300 (2007).

20. Caldwell, J.M. et al. Histologic eosinophilic gastritis is a systemic disorder associated with blood and extragastric eosinophilia, TH2 immunity, and a unique gastric transcriptome. J. Allergy Clin. Immunol. 134, 1114-1124 (2014).

21. Bochner, B.S. Road signs guiding leukocytes along the inflammation superhighway. J. Allergy Clin. Immunol. 106, 817-828 (2000).

22. Woodruff, P.G. et al. Genome-wide profiling identifies epithelial cell genes associated with asthma and with treatment response to corticosteroids. Proc. Natl. Acad. Sci. USA 104, 15858-15863 (2007).

23. Shum, B.O. et al. The adipocyte fatty acid-binding protein $\mathrm{aP} 2$ is required in allergic airway inflammation. J. Clin. Invest. 116, 2183-2192 (2006).

24. Zhen, G. et al. IL-13 and epidermal growth factor receptor have critical but distinct roles in epithelial cell mucin production. Am. J. Respir. Cell Mol. Biol. 36, 244-253 (2007).

25. Li, R.W. \& Gasbarre, L.C. A temporal shift in regulatory networks and pathways in the bovine small intestine during Cooperia oncophora infection. Int. J. Parasitol. 39, 813-824 (2009).

26. Blanchard, C. et al. Eotaxin-3 and a uniquely conserved geneexpression profile in eosinophilic esophagitis. J. Clin. Invest. 116, 536-547 (2006).

27. Ikuse, T. et al. Microarray analysis of gastric mucosa among children with Helicobacter pylori infection. Pediatr. Int. 54, 319-324 (2012).

28. Wen, S., Felley, C.P., Bouzourene, H., Reimers, M., Michetti, P. \& PanHammarstrom, Q. Inflammatory gene profiles in gastric mucosa during Helicobacter pylori infection in humans. J. Immunol. 172, 2595-2606 (2004).
29. Truong, K. \& kkura, M. The cadherin superfamily database. J. Struct. Funct. Genomics 2, 135-143 (2002).

30. Shapiro, L. \& Weis, W.I. Structure and biochemistry of cadherins and catenins. Cold Spring Harb. Perspect. Biol. 1, a003053 (2009).

31. Stappert, J. \& Kemler, R. A short core region of E-cadherin is essential for catenin binding and is highly phosphorylated. Cell Adhes. Commun. 2, 319-327 (1994).

32. Jou, T.S., Stewart, D.B., Stappert, J., Nelson, W.J. \& Marrs, J.A. Genetic and biochemical dissection of protein linkages in the cadherin-catenin complex. Proc. Natl. Acad. Sci. USA 92, 5067-5071 (1995).

33. Whittard, J.D. et al. E-cadherin is a ligand for integrin alpha2beta1. Matrix Biol. 21, 525-532 (2002).

34. Taraszka, K.S., Higgins, J.M., Tan, K., Mandelbrot, D.A., Wang, J.H. \& Brenner, M.B. Molecular basis for leukocyte integrin alpha(E)beta(7) adhesion to epithelial (E)-cadherin. J. Exp. Med. 191, 1555-1567 (2000).

35. Seminario, M.C., Sterbinsky, S.A. \& Bochner, B.S. Beta 1 integrindependent binding of Jurkat cells to fibronectin is regulated by a serinethreonine phosphatase. J. Leukoc. Biol. 64, 753-758 (1998).

36. Lehnert, K., Print, C.G., Yang, Y. \& Krissansen, G.W. MAdCAM-1 costimulates $T$ cell proliferation exclusively through integrin alpha4beta7, whereas VCAM-1 and CS-1 peptide use alpha4beta1: evidence for "remote" costimulation and induction of hyperresponsiveness to B7 molecules. Eur. J. Immunol. 28, 3605-3615 (1998).

37. van Seventer, G.A. et al. Analysis of T cell stimulation by superantigen plus major histocompatibility complex class II molecules or by CD3 monoclonal antibody: costimulation by purified adhesion ligands VCAM-1, ICAM-1, but not ELAM-1. J. Exp. Med. 174, 901-913 (1991).

38. Shimizu, Y., van Seventer, G.A., Horgan, K.J. \& Shaw, S. Costimulation of proliferative responses of resting CD4 + Tcells by the interaction of VLA-4 and VLA-5 with fibronectin or VLA-6 with laminin. J. Immunol. 145, 59-67 (1990).

39. Abonia, J.P. et al. Involvement of mast cells in eosinophilic esophagitis. J. Allergy Clin. Immunol. 126, 140-149 (2010).

40. Berg, R.W., Yang, Y., Lehnert, K. \& Krissansen, G.W. Mouse M290 is the functional homologue of the human mucosal lymphocyte integrin HML-1: antagonism between the integrin ligands E-cadherin and RGD tripeptide. Immunol. Cell Biol. 77, 337-344 (1999).

41. Grundemann, C. et al. Cutting edge: identification of E-cadherin as a ligand for the murine killer cell lectin-like receptor G1. J. Immunol. 176, 13111315 (2006).

42. Salimi, M. et al. A role for IL-25 and IL-33-driven type-2 innate lymphoid cells in atopic dermatitis. J. Exp. Med. 210, 2939-2950 (2013).

43. Ito, M., Maruyama, T., Saito, N., Koganei, S., Yamamoto, K. \& Matsumoto, N. Killer cell lectin-like receptor G1 binds three members of the classical cadherin family to inhibit NK cell cytotoxicity. J. Exp. Med. 203, 289-295 (2006).

44. Fuentebella, J. et al. Increased number of regulatory Tcells in children with eosinophilic esophagitis. J. Pediatr. Gastroenterol. Nutr. 51, 283-289 (2010). 